\title{
Human Development in Rural Settlements within the Centre Development Region of the Republic of Moldova
}

\author{
Mihai Hachi ${ }^{1}$, Vadim Cujbă ${ }^{2, 凶}$ \\ ${ }^{1}$ Academy of Economic Studies of Moldova, Republic of Moldova. \\ ${ }^{2}$ Tiraspol State University of Chișinău, Republic of Moldova.
}

\begin{abstract}
At present, the need for comparative studies of human development is increasingly emerging within an attempt to follow the level reached by states, regions or human communities in certain administrative-territorial units, aiming to assess the effectiveness of development policies applied by regional and local governments or administrations, beyond certain statistical indicators or series attesting to certain aspects of human development. In this context, the HDI applied by the UN includes four components of human development and provides a generalization of human development globally at the world's states level. In our study, we intend to develop the given indicator, including a much larger number of indices and indicators at the level of the 613 settlements within of the Centre Development Region, in the context of the implementation of the Regional Development Strategy of the Republic of Moldova.
\end{abstract}

Keywords: Human Development Index, Centre Development Region, demography, infrastructure.

\section{Introduction}

The purpose of the study is to estimate and determine the spatial differences of the Human Development Indicator (HDI) in the rural areas of the Center Development Center, taking into account several aspects of development. The intentions to synthesize the huge number of human development indicators in one, had led to the emergence of a synthetic indicator, IDU (Human Development Index), of which we hear about in the 1990s of the last century and which currently serves as one of the main indicators used by UNDP in its attempt to differentiate the world's states and 
follow the trajectories they have had over time. In the study, we proposed to develop the given indicator by including a larger number of indices and indicators at the level of the 613 settlements in the Center Development Region, in the context of the Law on Regional Development implementation in the Republic Moldova [1].In this respect, the level of settlements' development assessment, in the authors' opinion, it is necessary to follow the correctness of state interventions in terms of the use of different instruments for socio-economic development, the level they have reached in various areas, evaluation of the existing gap, etc.

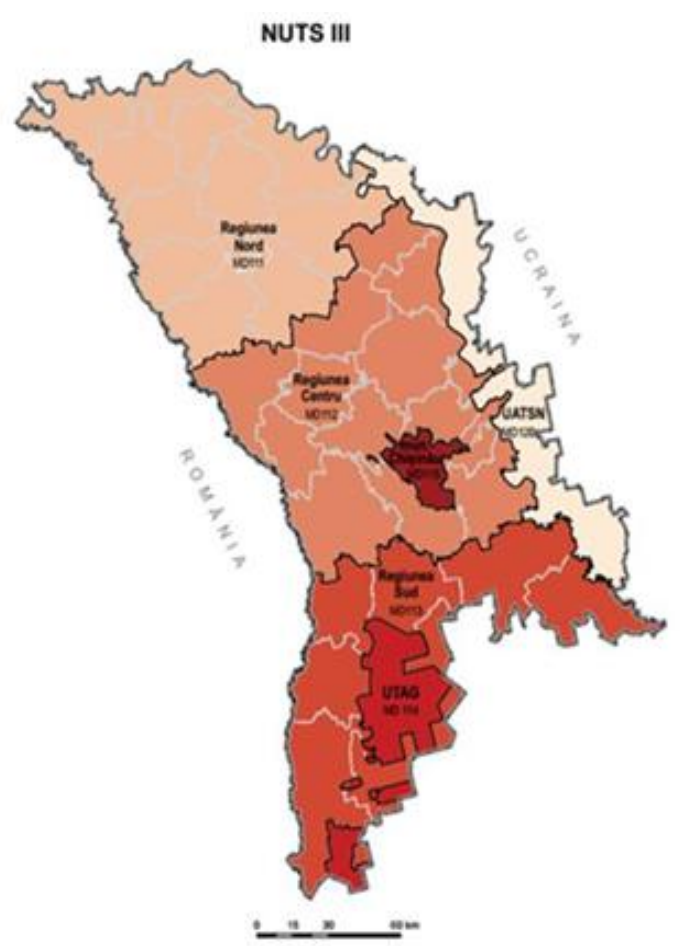

Figure 1: The Center Development Region in the context of Moldova's development regions

In terms of territory, C.D.R. is situated in the central part of the Republic of Moldova, having territorial boundaries with four other development regions in the country (North, South, Transnistria (Eastern Region) and (Chișinau) as well as the North-East Development Region of Romania (west side) (fig. 1).

The C.D.R. is the largest as surface and population. Itcomprises 13 districts (administrative-territorial units of level II), consisting of administrative-territorial units of level I (villages, communes and cities): 256 villages, 329 communes and 14 cities. The number of settlements in the region accounts for $36.6 \%$ of the total number within the country [2]. Concerning residence area, the share of the rural population represents $80.6 \%$ (2017), of the region's total population (Table 1). 


\section{Materials and methods}

In order to objectively evaluate the Human Development Index for the 613 settlements within the Center Development Region, the socio-demographic, economic and infrastructure components have been assessed. The database included 4 indicators referring to the socio-demographic component: the population number, population dynamics in the period 1998-2015, demographic pressure and demographic aging. The economic component and the infrastructure included: the number of economic units, the number of employees, the municipal budgets' own incomes, households with centralized and own water supply and sewage system, households with centralized gasification system, paved roads in good and very good condition. The statistical, mathematical, cartographic, comparison methods, and for cartographic representation - GIS were used. A large amount of information was collected from specialized institutions in the country, such as the National Bureau of Statistics, the Ministry of Information Technology and Communications of the Republic of Moldova, the Central Development Agency, etc. Data from the latest Population and Housing Census in 2014 was also used.

The HDI at the villages or regions level does not show the territorial situation within them, knowing that development is disproportionate and territorially discontinuous. In research we started with the human component that dictates through its quantitative and qualitative aspects the trends of evolution of the territorial system to which it belongs, representing an essential structuring element of the entire territory. The relationship between population and territory is observed through socio-demographic, economic, ecological components, etc.The economic component was analyzed in terms of the indicators: the number of economic units/1000 inhabitants, the number of employees / the number of persons able to work, the rate of their own budget revenues and also as it was mentioned the infrastructure dimension.

The aging of the population in a settlement has a double significance, on the one hand, a large share of the aging population and a high life expectancy can be interpreted as an expression of a high standard of living for the population, and on the other hand, a large proportion of the elderly population from the total population denotes increasing the economic "burden" and maintenance costs. Aging has been reported to the Bojio-Garnier aging scale (Table 4).

Another indicator taken into account is the age dependency ratio that represents the ratio of the number "age dependent" people (people under 15 years and above $57 / 62$ years $)^{2}$ and working age population (16 - 57/62 years) expressed to 100 persons (\%).

\footnotetext{
2 Inthe Republic of Moldova, the retirement age is currently 57 years for women and 62 years for men with a tendency to increase by 2026 to 62 years for women and 65 for men respectively
} 
Calculation of population dynamics allows us to assess the degree of population stability, positive population growth over a period of 18 years (2008-2015) allows us to identify the demographic perspective of the population as: very good, good, stagnation, slow decline and irreversible decline.

A final index taken into account - the population number - has both economic and social significance. As a rule, large and very large localities are less vulnerable to the socio-economic transformation that Moldova has experienced. These are also considered to be susceptible to the placement of capital and in terms of greater opportunities for investments in social, economic, technical-urban infrastructure, etc. We distinguish, in this concern, 5 categories of settlements:

1. 5001+inhabitants - very large;

2. 2001-5000 inhabitants - large;

3. 1001-2000inhabitants - average;

4. 201-1000 inhabitants - small;

5. Very small - under200 inhabitants [7, p.42].

In calculating the HDI typology of localities on the socio-demographic dimension the weighted average of the indices was used and the geometric mean of the four indices and indicators taken into account. The HDI varies on a scale between 0 and 1 , and the level of human development is higher as it is closer to 1.

Infrastructure and economic component aspects, are indissociably linked, both reflect the level of welfare of the population, providing the person with biological needs, psychological, social and family satisfaction. In this context, the analyzed indicators reflect both the current state and the development prospects of the settlements, especially at the level of communes. The commune as an administrative-territorial unit is the last hierarchical level for which statistical surveys on different dimensions are carried out, apart from demographic ones, for regional planning and development. Thus, the economic and infrastructure dimensions can be rightly considered as both causes and consequences in the process of socio demographic transformations.

\section{Results and discussions}

Drawing on the experience of the European Union, Republic of Moldova through the aspiration of European integration and the commitments it has made, in order to ensure effective and sustainable socio-economic development, approved the Regional Development Law in 2006 - which provides the legal framework for the development of the country through development regions. According to the law, the geographical area of the Republic of Moldova was divided into six development regions: the South Development Region, the Center Development Region, the North Development Region, the Nistrean Administrative-Territorial Unit (NUTS), also called the 
administrative-territorial unit from the left bank of the Dniester), AdministrativeTerritorial Unit Gagauzia and Chisinau.

Based on this division, the demographic and economic power of the development regions has been taken into account, so that they can meet the financial challenges for their administrative structures, the ratio of them being unbalanced (Table 1).

Table 1: The comparative characteristic of the Development Regions of the Republic of Moldova (01.01.2017)

\begin{tabular}{|l|c|c|c|c|c|}
\hline Development Regions & $\begin{array}{c}\text { Number of } \\
\text { present } \\
\text { population } \\
\text { thousands of } \\
\text { inhabitants) }\end{array}$ & $\begin{array}{c}\text { The share of } \\
\text { population } \\
\text { from } \\
\text { total(\%) }\end{array}$ & $\begin{array}{c}\text { Population ratio } \\
\text { vs. most populated } \\
\text { region D.R. } \\
\text { (R.D. Centre=100) }\end{array}$ & $\begin{array}{c}\text { Surface } \\
\left(\mathrm{km}^{2}\right)\end{array}$ & $\begin{array}{c}\text { Surface } \\
\text { from the } \\
\text { total } \\
(\%)\end{array}$ \\
\hline 1. D. R. North & 931,2 & 27,6 & 92,9 & 10.014 & 29,6 \\
\hline 2. D. R. Centre & 1002,3 & 29,7 & 100 & 10.636 & 31,4 \\
\hline 3. D. R. South & 504,4 & 15,0 & 50,5 & 7.379 & 21,8 \\
\hline 4. Chisinau municipality & 779,0 & 23,2 & 78,1 & 572 & 1,7 \\
\hline $\begin{array}{l}\text { 5. Autonomous } \\
\text { Territorial Unit of } \\
\text { Gagauzia (GagauzYeri) }\end{array}$ & 152,2 & 4,5 & 15,2 & 1.848 & 5,5 \\
\hline $\begin{array}{l}\text { 6. The Administrative- } \\
\text { Territorial Units of the } \\
\text { Left Bank of the } \\
\text { Dniester }\end{array}$ & $470,6^{1}$ & 12,3 & 47,2 & 3.401 & 10,0 \\
\hline \multicolumn{1}{|c|}{ Total } & $3839,7^{2}$ & 100 & & & \\
\hline
\end{tabular}

Source: adapted according to statistica.md and the data of the development agencies of the Republic of Moldova. ${ }^{1}$-according to the official data of the authorities in the Administrative - Territorial Units on the left bank of the Dniester, $2017 .^{2}$ - calculated for the current population at 01.01.2017, without NUTS.

So the ratio between the most populated and the least populated region is 6.6, or as an area of 18,6 times (Table 1). Currently, out of the six development regions expected to be implemented, only 4 are functional (The Chisinau municipality as a development region is to be started in 2018 and the functionality of the NUTS' situation will depend on its conjunctural evolution).

In the latest UNDP report published in 2016, Moldova's IDU level was 0.699, ranking 107 out of the 188 world states mentioned in the report [5]. Over time, the IDU of Moldova has oscillated quite a lot. Thus, in 2000, Moldova went down to the lowest level of 0.597 , or $8.4 \%$ over 1990 . This was due to changes in social life, deepening the economic and political crisis, reducing the living standards of the population. The deep decline in the Republic of Moldova in the first years of independence has marked its significance at the European level through the lack of viable solutions to overcome the crisis.

Despite the increase in the IDU level in 2000, Republic of Moldova remains the country with the lowest level of this index compared to the states in the region. Transition period went slowly, compared to other Central and South-Eastern 
European countries, most of the European Union. If in the early 1990s, the Republic of Moldova exceeded Albania, currently occupies the last place in the region (fig.2a,2b). In this regard, it is necessary to implement as much as possible reforms on all the dimensions of the socio-economic and political spheres in order to advance towards the path to EU membership.

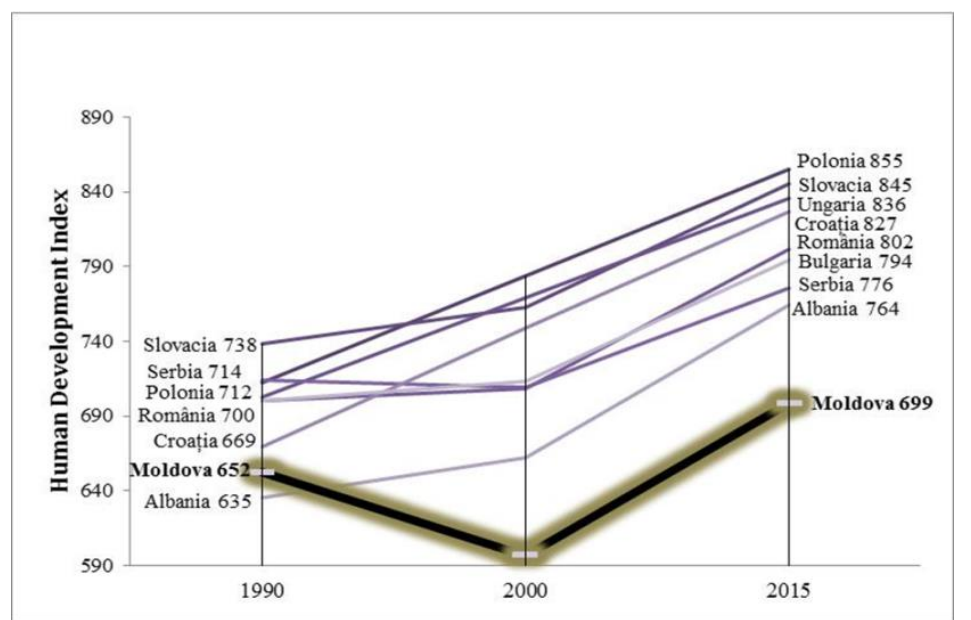

Figure 2a: The value of the Human Development Index of the Republic of Moldova compared to other states in Central and South-Eastern Europe

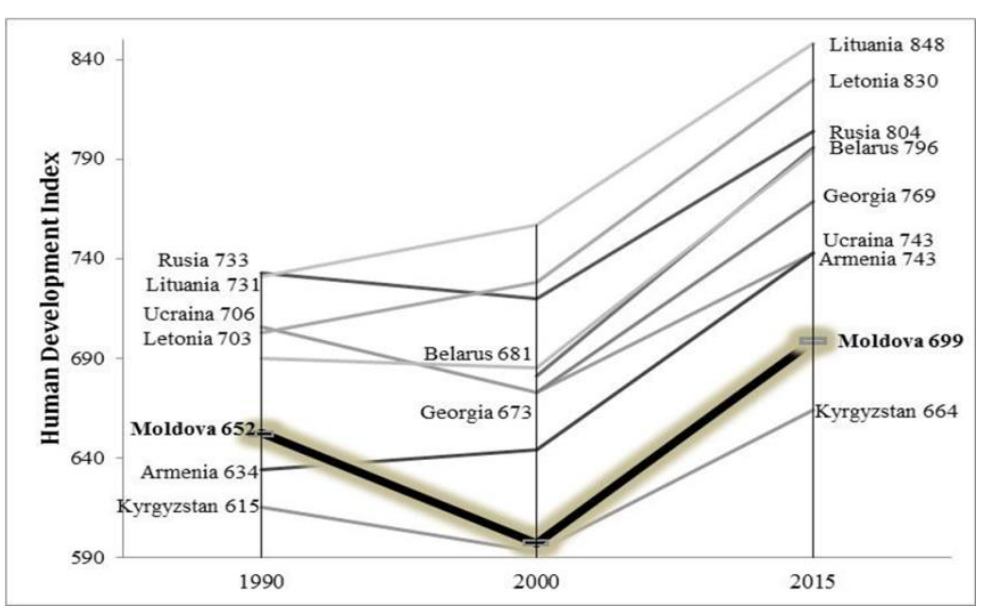

Figure 2b: The value of the Human Development Index of the Republic of Moldova compared to other states ex-USSR

The geodemographic dimension. For the C.D.R. differentiation based on the demographic component, the indicators and indicators were taken into account: demographic aging, population, demographic pressure and population dynamics in the period 1998-2015. In our opinion, these 4 quantitative and qualitative indicators allow for an objective evaluation of the geodemographic situation at the level of the 
primary administrative-territorial units. From the perspective, it is possible to extend the study to other relevant demographic indicators..

A first indicator taken into account is demographic aging. The aging degree was reported to the Bojio-Garnier scale (Table 4).

Thus, demographic aging data systematization at the primary settlements of Central Development Region shows an average demographic aging of $14.4 \%$, which is an average stage of aging in the region. The rate of demographic aging in the C.D.R. is $1.2 \mathrm{pp}$ (percentage points) lower than the average for the republic and much lower compared to N.D.R. and districts from the left side of the river Dniestr, which have the highest values of aging (Table 4).

Table 4: The aging degree within C.D.R. settlements, 01.01.2017

\begin{tabular}{|c|c|c|c|c|}
\hline Rank & $\begin{array}{c}\text { Share of aging } \\
\text { population (\%) }\end{array}$ & $\begin{array}{l}\text { The aging degree of the } \\
\text { settlements } \\
(\%)\end{array}$ & $\begin{array}{l}\text { Number of } \\
\text { settlements } \\
\text { within C.D.R. }\end{array}$ & $\begin{array}{l}\text { \% of all } \\
\text { settlements in } \\
\text { C.D.R. }\end{array}$ \\
\hline 1 & $<8$ & Young settlements & 18 & 2,9 \\
\hline 2 & $8-10$ & $\begin{array}{c}\text { Relatively young } \\
\text { settlements }\end{array}$ & 25 & 4,1 \\
\hline 3 & $10-12$ & $\begin{array}{l}\text { Settlements on the aging } \\
\text { threshold }\end{array}$ & 71 & 11,6 \\
\hline \multicolumn{5}{|c|}{$\begin{array}{c}\text { Aging settlements } \\
\text { over } 12 \% \text { demographic aging threshold }\end{array}$} \\
\hline \multirow[t]{2}{*}{4} & $12-14$ & $\begin{array}{l}\text { Settlemens in the early } \\
\text { stage of aging }\end{array}$ & 126 & 20,5 \\
\hline & 14-16 & Medium aging settlements & 128 & 20,8 \\
\hline \multirow[t]{2}{*}{5} & $16-18$ & High aging settlements & 111 & 18,1 \\
\hline & $18+$ & $\begin{array}{c}\text { Very high-aging } \\
\text { settlements }\end{array}$ & 135 & 22,0 \\
\hline $\begin{array}{l}\text { Total or } \\
\text { C.D.R. } \\
\text { average }\end{array}$ & & & 613 & 14,4 \\
\hline $\begin{array}{c}\text { The country } \\
\text { average }\end{array}$ & & & 1682 & 15,6 \\
\hline
\end{tabular}

Source: calculated based on NBS data.

Young settlements with aging under $8 \%$ are the fewest (18), with a share of only $2.9 \%$ of the total number in the development region. The majority of young settlements are small and very small, with population in stabilization course, irrelevant sometimes in comparative aspect, with a growing population above the regional or republican average. Among these are some localities with a predominantly Roma population, with fertility rates higher than other ethnic groups, for example (Vulcanești/Nisporeni, Palanca and Ursari/Calaraș, etc.). Only 3 of them have a commune status, even if their size is small or very small (TrestieniValley/Nisporeni (737 inhabitants), Crihana, Orhei (194 inhabitants) and Socoleni, AneniiNoi (452 inhabitants).. 
Another 96 settlements (15.7\%) have an aging index below the demographic aging threshold of $12 \%$, according to the Bojio-Garnier scale. The highest share of settlements in the middle and high level of demographic aging is with 254 (41.3\%) and $246(40.1 \%)$. The relatively good situation in this aspect is due to the positioning towards the capital (Chisinau), as well as to the later demographic transition than in N.D.R.

Geographically, the most significant aging is in A.T.U. Teleneşti, Ungheni, Şoldăneşti, Rezina being on the northern border of the region, as well as the settlements in the eastern and southern extremities (fig. 3).

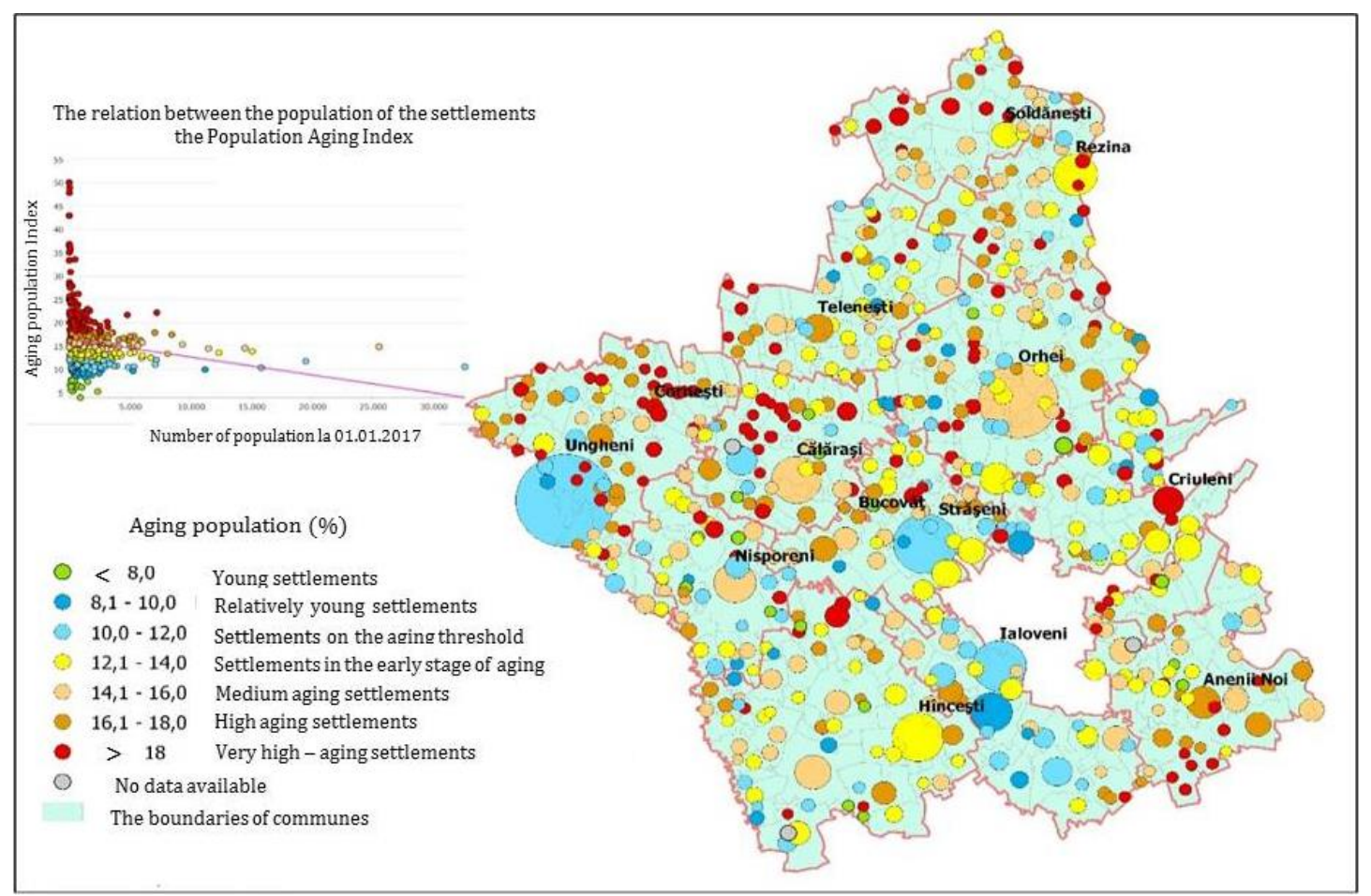

Figure 3: The demographic aging of the population in the C.D.R.

Another socio-demographic feature taken into account is the population number. It has both economic and social significance. As a rule, large and very large settlements are less vulnerable to the socio-economic changes that Republic of Moldova has experienced. Large settlements are characterized by greater vitality, with a higher degree of stabilization. Among the five categories of cities by number of inhabitants have the highest share have small (37.7\% of total) and average ones (27.6):

1. 5001+ inhabitants - very large - 21 settlements $(3,4 \%)$;

2. 2001-5000 inhabitants - large -113 settlements $(19,3 \%)$;

3. 1001-2000 inhabitants - average - 158 settlements $(27,6 \%)$;

4. 201-1000 inhabitants - small - 222 settlements $(37,7 \%)$; 
5. Very small - below 200 inhabitants - 71 settlements (12,1\%).

The ratio between medium and large settlements compared to small and very small is $50: 50$.

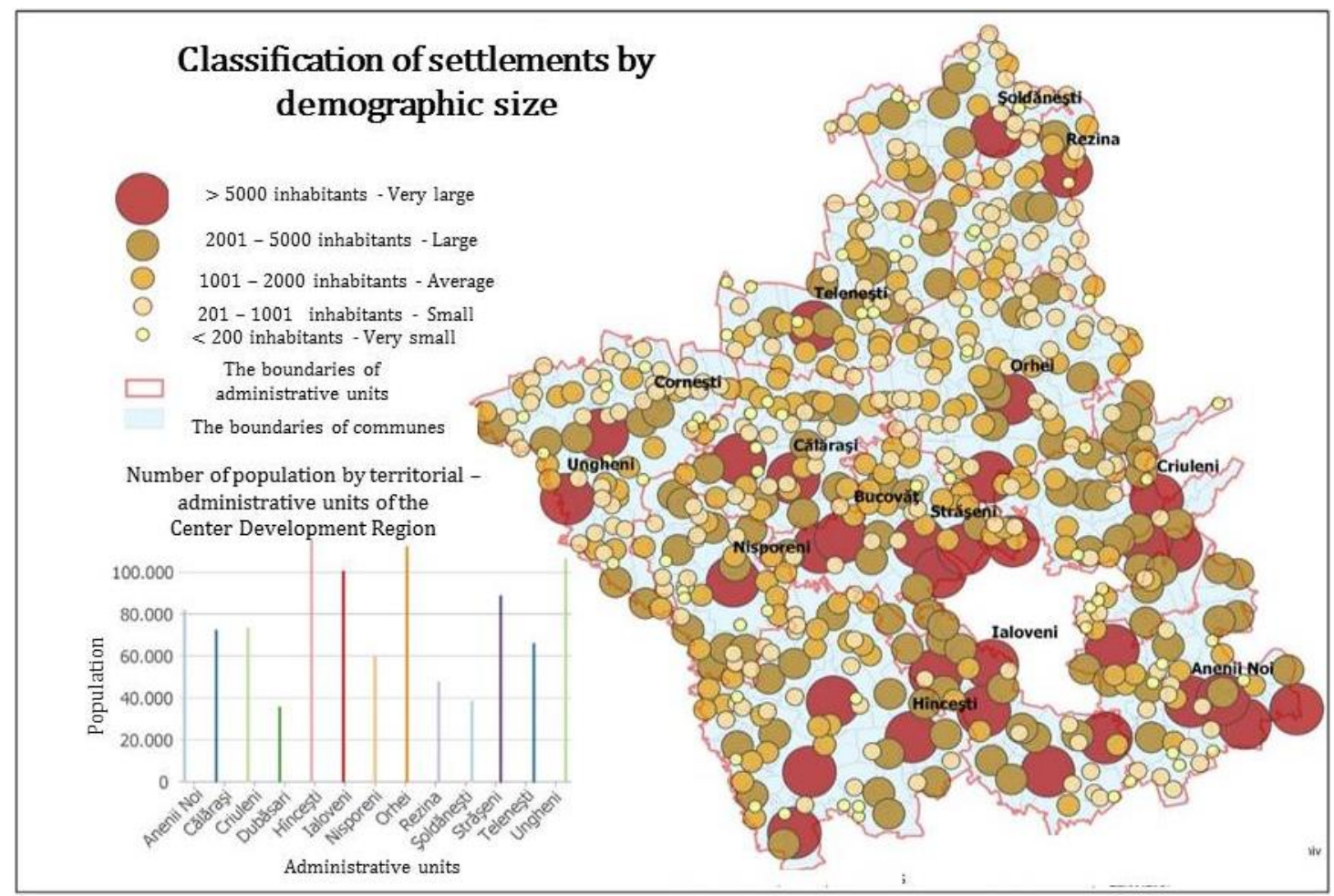

Figure 4: The C.D.R. settlements according to the number of population present at 01.01.2017

Most of the large and very large settlements are located in the neighboring districts of Chisinau: Ialoveni, Straseni and Anenii-Noi, while the Ungheni and Rezina raions have the largest number of small and very small settlements. It is also different the number of population at administrative territorial units by district level. Thus, the district with the largest population in the C.D.R.; Hancesti exceeds the districts Rezina, Şoldăneşti and Dubăsari, which represent 41\%, 34\% and 28\%, respectively, compared to the most populous district. This must be taken into account in the sharing of financial and other resources in the context of decentralization, foreseen by the administrative-territorial reform to be implemented (fig.4).

Regarding the population dynamics in the period 1998-2015, the data show different evolutions in the settlements, according to geographic position within the region and their size. The data obtained as a result of the processing of information on population inputs and outputs (immigration and birth rates were provided by immigrants and emigration and mortality outcomes) allowed us to identify the degree of population stability and to create a typology of population dynamics in - an 
interval of 18 years. Analysis of population dynamics confirmed the hypothesis of a large decline of the population practically in all regions' settlements.

This allowed us to develop a typology of population dynamics, starting from these 3 trends in geodemographic evolution. Thus, although the geodemographic situation in the R.D. Center is more stable compared to other regions (except for the municipality of Chisinau), however, most of the settlements (371) recorded a population decline from $-1 \%$ to $-66 \%$.

The tendency to decrease the number of inhabitants from a geodemographic point of view can be grouped into three distinct areas:

1. Codrilor area (communes from Calaraș, Teleneşti, Ungheni);

2. The peripheral area of N-E (communes from the rayons of Şoldăneşti, Rezina);

3. The area in the Lăpuşna valley (communes from Hîncesti and Nisporeni districts). The main causes of the decline stem due the isolated location, the lack of local opportunities, the remoteness of the centers of territorial polarization, as well as the internal and external migration. A distinct group of settlements are those that have stagnated, with the number of population varying within the limits $-1 \%$ și $1 \%$.

The third typological group of geodemographic dynamics concerns settlements which have registered population growth from 1 to over $40 \%$, which is significant for this period of instability and socio-economic transformations. Locations with population growth tendencies can be grouped in 3 areas:

1. The peripheral area of Chisinau municipality (about 40 communes);

2. Prut Valley area (about 35 communes);

3. The peripheral area of Orhei (about 20 communes).

The highest degree of population stability in terms of its dynamics is represented by the large and medium-sized settlements, favorably positioned to the capital or important regional centers such as Orhei, Ungheni, the neighborhood of Iasi and Husi, Romania. The positive trend of population growth in the settlements in the Prut Valley area may also be due to the EU Neighborhood Policy in relation to Moldova, which was the Small Border Traffic, that started in 2009.The last indicator analyzed from the socio-demographic component is the demographic dependence. The age dependency ratio is the ratio of the number of "dependent" people. This indicator of the economic "burden" that the productive population has towards the population maintained in most of the settlements is medium to low, the rhythm of high demographic aging, the slow growth of the population due to the continuation of the migration will determine its growth, those who will bear the economic "burden" is going to be the working population.

Based on the calculation of the weighted average of the four indices and indicators of the socio-demographic dimension taken into account $\left(\mathrm{X}_{\text {index }}=\mathrm{X}\right.$ L.S.G.D.C. 46 (2): $49-63$ 
$\min x / \max _{x}-\min _{x}$ ), as well as the geometric mean of the indices (IDU general $=\sqrt{ } \mathrm{Ik}{ }^{*} \mathrm{I}_{\mathrm{k}{ }^{*}} \mathrm{I}_{\mathrm{kn}}$ ) four types of localities have been identified:

Settlements with a high socio-demographic development- an index of over 0,700 - 10 localities, $1,6 \%$ of the total; The general profile of these localities is as follows: there are very large and large villages, 9/10 have a commune status, they have an advantageous position towards Chisinau or district centers, they have a population with a stable evolution, registering a numerical increase, both on the basis of the natural balance and the positive mechanical balance. These settlements could become in close proximity to the towns, some of them having the role of local polarization centers (Costeşti, Peresecina, Truseni, etc.).

Settlements with a high average socio-demographic development (0.601$0.700)$ - 107, 17.5\%;Most of these settlements have medium and large dimensions, having a high socio-demographic development due to favorable location to the capital, good transport links with Chisinau municipality. The degree of population stabilization is medium. Several of them are marked by population migration, especially external migration.

Settlements with low average socio-demographic development $(0,501-0,600)$ 356 settlements, $58 \%$; It is the largest group (about $60 \%$ ) of the total. Most of them are medium and small towns, being part of a commune. The degree of population stabilization is reduced by the structural distortion of the population, with low natural population growth rates and increased migration.

Settlements with low socio-demographic development (less than 0.500) - 113 settlements, $18.4 \%$. This includes villages with a long-lasting involution of population number. These settlements recorded the largest decline in population dynamics, with limited demographic restoration possibilities. The lack of economic and social opportunities strengthens their vulnerability in terms of demographic and existential prospects.

Sustainable economic and social development of rural settlements is indispensable for improving rural infrastructure, supporting entrepreneurship and developing public services. Thus, for the correct implementation of balanced territorial development policies and the elimination of existing social inclusion among rural communities an objective and systematic assessment of the causes is necessary, in particular, economic ones, which maintain this gap.

Our calculations and estimations have allowed us to develop two synthetic indicators that reflect the level of the economic dimension and rural infrastructure. According to our assessments made from the cartographic materials, we have found that in a local profile, the level of economic development and infrastructure presents notable geographic disparities, since they are interdependent and sensitive domains in the local development process (Figure 5, 6). 


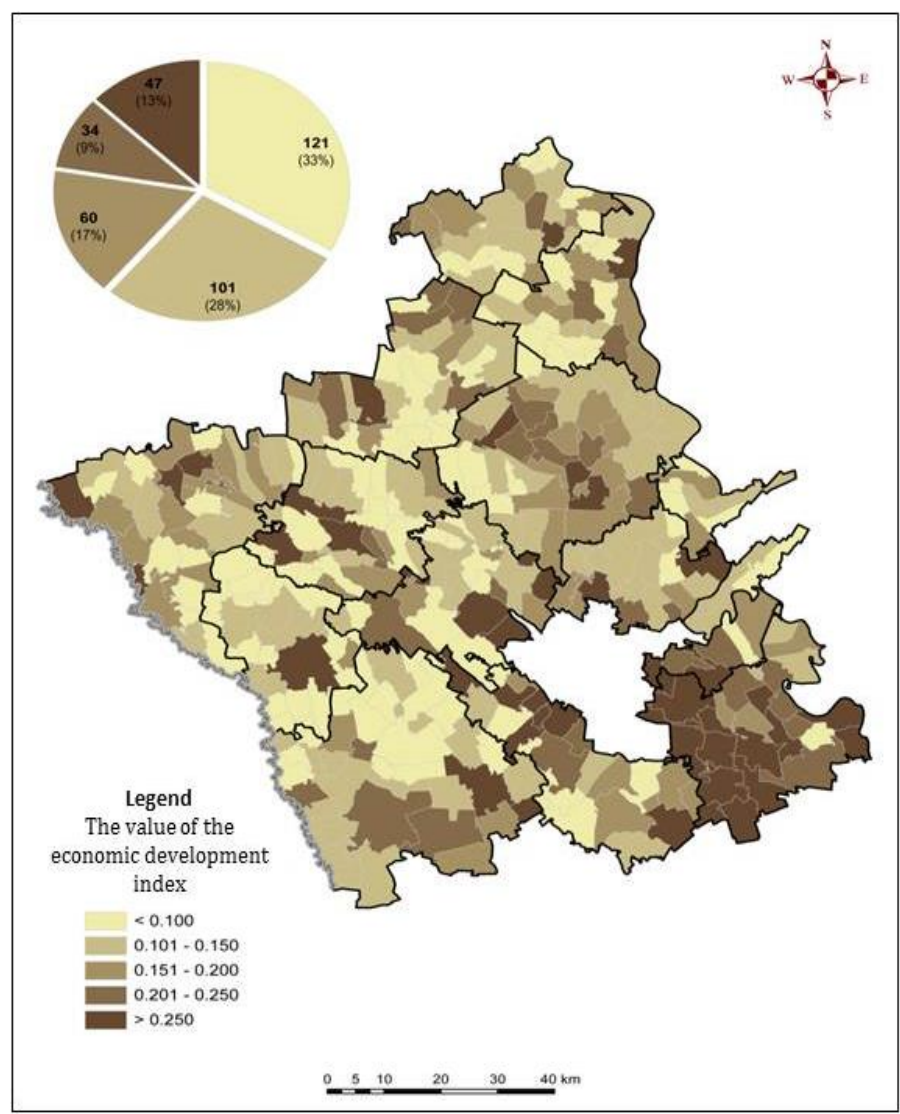

Figure 5: The Economic Development Index of C.D.R. settlements

For the Center Development Region, there are significant discrepancies in the economic development process. Thus, the ratio between the least developed communities and the communities with a more favorable economic situation is 6 to 1 .

A relatively satisfactory situation is specific for the settlements in the proximity of the Chisinau mun. (Anenii-Noi, Ialoveni, Criuleni and Straseni), including in the cities that have the function of rayon centers. The highest values of the Economic Development Index were estimated for urban areas: Ungheni $(0,452)$, Hîncești $(0,627)$, Ialoveni $(0,664)$, Orhei $(0,684)$ and AneniiNoi $(0,690)$ and some large rural settlements in AneniiNoi, with comparable indicators such as Mereni $(0,578)$ and Bulboaca $(0,419)$. At the same time in Hîncești, Nisporeni and Ungheni districts there were formed areas with compact localities, continuously characterized by underdeveloped entrepreneurial activity, small number of economic units, low number of employees in enterprises and high level of unemployment. In the Nisporeni district there were recorded the rural areas with the lowest values of the Economic Development Indicator, such as: Vânători (0.023), Călimăneşti (0.029), Bolțun and Marinici (0.042). 


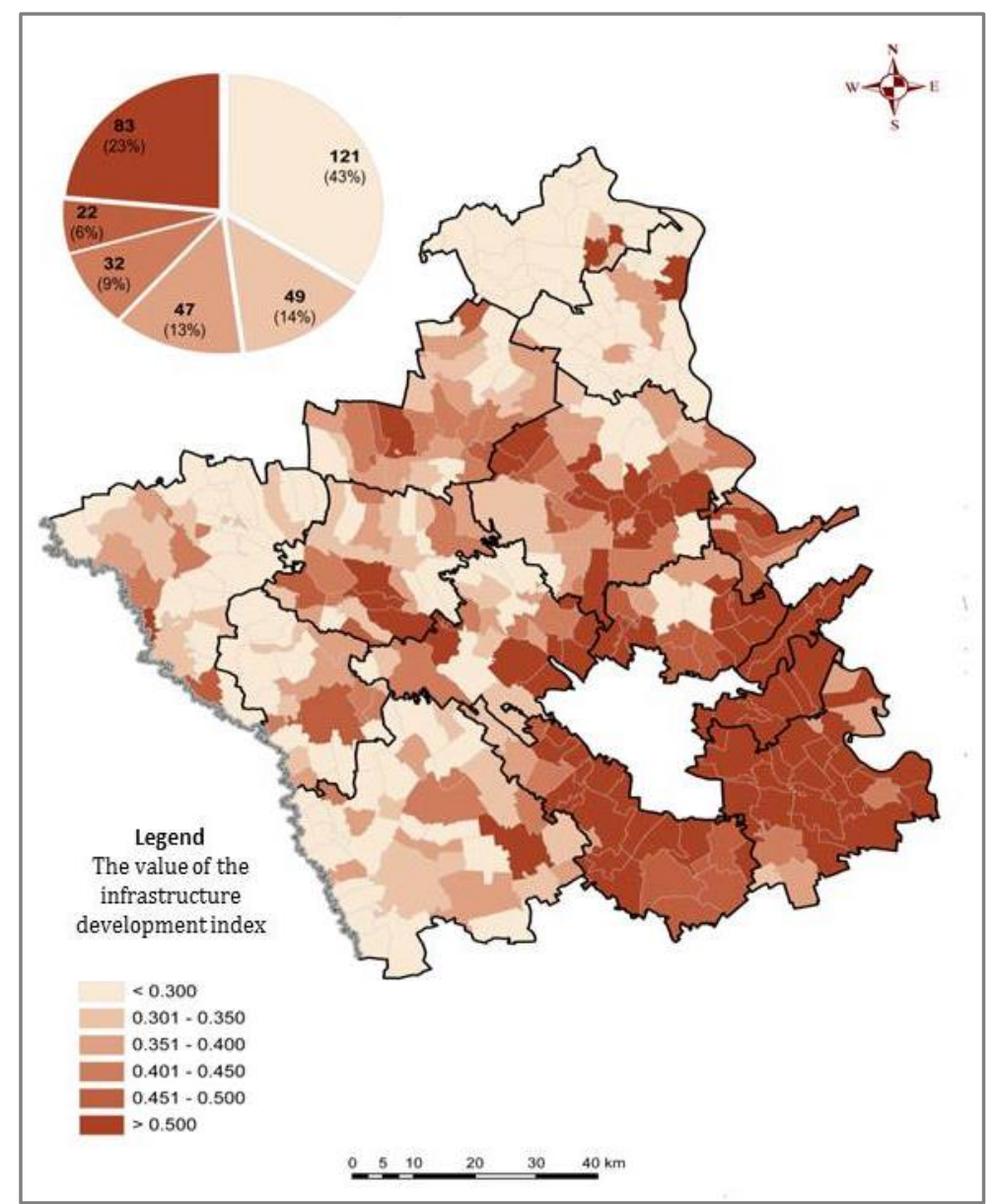

Figure 6: The Infrastructure Development Index of C.D.R. settlements

The fundamentals of economic boost and the increase in living standards in rural areas can only be ensured through the qualitative development of the infrastructure or the technical and municipal endowment as well as the related services. As part of the population and housing census in 2014, the main features of the housing conditions of the country's population have been achieved, with significant changes in the period between the last two censuses 2004 and 2014.Considering that at present the settlements of the C.D.R., in particular the Chisinau municipality, are supplied with surface water mainly from the Dniester River through the power station near VadulluiVoda, the access rate of households to centralized supply systems is higher in proximity to the capital; and exceeds $80 \%$. For rural areas in the western part of the region, a lower housing insurance rate with access to centralized drinking water supplies is specific, in some communes even under $20 \%$ of households - due to the relatively recent implementation of some 
projects ensuring drinking water supply from the Prut river for Ungheni, Nisporeni and Hîncesti districts.

The sewerage systems expansion remains one of the main problems of rural areas both in the region and throughout the country. Although housing access to the system has increased visibly in all C.D.R. districts, this is mainly due to the construction of own systems besides households, but without observing sanitary and epidemiological rules, thus endangering both the health of the population and of the environment. At the same time, the lack or poor technical condition of existing treatment plants will not create the possibility in the near future to qualitative development of sewerage services.

The expansion, in particular, of natural gas networks has been a total failure at both national and regional level. Despite the fact that a very extensive legal framework was established in the Republic of Moldova regarding the development of natural gas activities in line with the main legislative acts in the field of Energy Law (1998) and the Gas Law (1998), including the Government Decision on measures to accelerate the local gasification process of localities (2008), and the Country Energy Strategies elaborated for different stages, 2010, 2020 and 2030, these did not substantially contribute to the increase of the insurance level of the population with centralized natural gas supply services. High cost of connection to these networks has restricted the access of resident population to these services for financial reasons also in view of the socio-economic crisis and the limited financial possibilities of households. Thus, official data on the gasification rate of rural communities indicates the existence of substantial territorial disparities within the C.D.R.. The southeast of the region, consisting of the Anenii - Noi, Criuleni, Dubăsari and Ialoveni districts, has emerged as a concentration pole of the highest gasification settlements, which in some cases exceeds $90 \%$ of the number of households. From the point of view of the interconnection of the households and the economic enterprises in the district centers, two ramifications were formed, including the rural communities with a gasification rate of $10-30 \%$.The first branch is in the direction of Straseni - Calarasi Teleneşti - Soldanesti. The second branch comprises the segment of settlements comprised between Măgdăceşti - Orhei, with higher values of the gasification rate. At the same time, a large part of the area of Hîncesti, Nisporeni, Ungheni, Teleneşti, Rezina and Şoldăneşti districts there are more non-gasified rural communities.

\section{Conclusions}

1. The socio-demographic dimension of human development has a particular significance in the HDI calculation, being given the role and place of the population in quantitative and qualitative terms. It has the main role of social, economic and territorial development policies. 
2. The systematization and analysis of socio-demographic indicators in th C.D.R. emphasized the trends and problems generated by the population evolution in time and space in the 613 settlements, the precision degree at primary level being quite high.

3. The greatest socio-demographic stability is represented by the large settlements and those situated in the neighborhood of the capital through the opportunities offered by it and the many connections. At the opposite pole, there are those isolated, medium and small settlements, more prone to the constant decline of the population.

4. Development policies applied in spatial profile, as well as the financial and material resources allocation, should take into account the current and prospective situation in order to better monitor and manage the sociodemographic component.

5. The public utilities infrastructure plays a decisive role in improving the population's life quality in the context of socio - economic deprivation and geodemographic transformations exclusion.

6. The efficiency and quality of public utility services is a factor of competitiveness and provides territorial cohesion due to the fact that it can attract investments in the less favored regions.

\section{Bibliography:}

MATEI C., HACHI M.,2014, Evoluția demografică a Republicii Moldova. Monografie. Chișinău. ASEM, 210 p. 18 c.a.

MÂTCU, M.; HACHI, M., 2008, Populația rurală a Republicii Moldova: cercetări geodemografice. Ch.: ASEM, 243 p.

*** Legea nr. 438 din 28.12.2006 cu privire la DezvoltareaRegionalăînRepublica Moldova/. http://lex.justice.md/index.php?action

*** http://lex.justice.md/md/312874/ Legea cu privire la organizareaadministrativ-teritorială a R. Moldova (accesat 11.08.2017).

*** Strategia de Dezvoltare Regională Centru 2016 - 2020, Ministerul Dezvoltării Regionale și Constructiilor, $52 \mathrm{p}$.

*** Raportul Național de Dezvoltare Umana 2015/2016. Republica Moldova - Inegaliți în dezvoltarea umană. 168 p.

*** Human Development Report 2016, 286 p. http://hdr.undp.org/sites/default/files/2016 human development report.pdf 
